\title{
PENGARUH UNSUR MILITARY TERHADAP DESAIN FASHION KALANGAN MUDA DI INDONESIA
}

\author{
Benhart Bhara Menoreh ${ }^{1}$, Sulistyo Setiawan ${ }^{2}$ \\ ${ }^{1}$ Jurusan Desain Produk, Fakultas Seni Rupa dan Desain, ITENAS, Bandung \\ ${ }^{2} J u r u s a n$ Desain Produk, Fakultas Seni Rupa dan Desain, ITENAS, Bandung \\ Email: o-bama@yahoo.com
}

\begin{abstract}
Abstrak
Techwear adalah perpaduan fashion dengan outdoor outfit dengan sentuhan military style, yang berfokus pada fungsi dan mengutamakan aspek aesthetics dan utility. Karakteristik utility tersebut sedikit banyak berdasarkan dari bentuk, siluet dan fungsi dari military uniform atau semua yang berkaitan dengan military. Dalam implementasinya, hasil desain produk dari techwear ini merupakan desain produk yang terinspirasi dari aspek yang ada pada military. Setelah penelitian dilakukan, terdapat beberapa masalah dan peluang dari ruang lingkup sarana bawa techwear ini, yaitu butuhnya desain produk sarana bawa bagi pengguna sepeda fixgear yang beraktifitas sehari-hari menggunakan sepeda fixgear. Dengan karakteristik dari fashion techwear yang optimal, seperti fitur Utility dan Waterproof, muncul peluang baru mengenai sarana bawa techwear ini, yang terinspirasi dari karakteristik fashion techwear dan military look. Didalam aspek tersebut masih banyak ruang untuk di eksplorasi lebih dalam secara desain dan fashion. Dengan adanya fashion techwear yang baru muncul dan berkembang di Indonesia, membuat trend fashion tersebut menarik untuk dibahas lebih dalam lagi. Penelitian ini dilakukan dengan menggunakan metode Studi Literatur yang menghasilkan sebuah kajian data yang relevan.
\end{abstract}

Kata kunci: Fashion, Techwear, Military Look, Utility..

\begin{abstract}
Techwear is a fusion of fashion with outdoor outfit with a touch of military style, which focuses on function and prioritizes aspects of aesthetics and utility. The utility characteristics are more or less based on the form, silhouette and function of military uniform or all related to military. In its implementation, the product design results of this techwear are product designs that are inspired from aspects that exist in the military. After the research was conducted, there were several problems and opportunities from the scope of this techwear carrying facility, namely the need for product design means to bring fixgear bicycles to daily activities using fixgear bikes. With the characteristics of optimal fashion techwear, such as the Utility and Waterproof features, new opportunities arise about the means of carrying these techwear, which are inspired by the characteristics of fashion techwear and military look. In this aspect there is still plenty of room for deeper exploration in design and fashion. With the new fashion techwear emerging and developing in Indonesia, making the fashion trend interesting to be discussed deeper. This research was conducted using the Literature Study method which produced a review of relevant data.
\end{abstract}

Keywords: guidance, instruction, direction for use, guideline.

\section{Pendahuluan}

Saat ini, pakaian merupakan salah satu kebutuhan primer yang harus dipenuhi oleh manusia. Lebih dari itu, pakaian juga merupakan cara bagaimana untuk menyampaikan pesan non verbal, seperti bagaimana cara berekspresi dalam lingkup sosial. Sama halnya dengan aspek military, pakaian militer tidak lagi digunakan sebagai seragam militer layaknya 'militer', melainkan digunakan sebagai kostum militer dalam kehidupan keseharian sebagai 'fashion'[1].

Sarana bawa barang atau sering disebut tas merupakan hal penting atau essential dalam kehidupan sehari-hari yang berfungsi sebagai alat bantu dalam hal membawa atau mengakomodir barang bawaan seseorang. Sarana

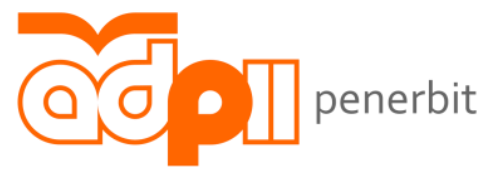

Penerbit Aliansi Desainer Produk Industri Indonesia 
bawa sudah ada dan dibuat sejak zaman prasejarah. Saat itu sarana bawa masih menggunakan bahan atau material alam baik dari tumbuh-tumbuhan maupun kulit hewan. Pada abad ke-18 masyarakat Barat mulai membuat tas yang difungsikan untuk perang. Tas ini dikhususkan bagi para anggota militer untuk membawa perlengkapannya ke medan perang. Pada tahun 1940-an unsur minimalis mulai masuk dan dipadukan pada tren busana, karena pengaruh unsur minimalis tersebut kemudian mempengaruhi desain sarana bawa pada masa itu yang disebut handbag. Mulai pada tahun 1960-an sampai sekarang tas semakin ke gaya yang lebih anak muda, dan juga material yang dipakai menjadi lebih beragam [2]

Pada perkembangannya, fashion techwear mengadaptasi unsur military pada karakteristik desain produk yang dihasilkan. Karena memang pada dasarnya produk yang diciptakan untuk keperluan dan perlengkapan militer memiliki aspek fungsi yang optimal, yaitu utility. Techwear mengadaptasi unsur military tersebut yang digabungkan dengan unsur fashion sehingga menghasilkan kebaruan dalam hal desain dan fashion, khususnya desain produk. Dalam techwear sendiri, utility merupakan aspek utama yang mengutamakan nilai guna suatu barang, serta aspek aesthetic yang sangat diperlukan dalam hal fashion.

Bertitiktolak dari hal-hal yang tersebut diatas, penulis akan melakukan analisis lebih jauh terhadap image pada unsur military yang menjadi dasar pada fashion techwear yang hasilnya dapat dijadikan sebagai masukan penggalian alternatif desain sarana bawa yang memudahkan bagi pengguna sepeda fixgear.

\section{Metodologi}

Penelitian ini diawali dengan proses penelitian menggunakan metode studi pustaka. Pengertian studi pustaka adalah mencari referensi teori yang relefan dengan kasus atau permasalahan yang ditemukan. Informasi tersebut didapatkan dari sumber seperti buku-buku, karya ilmiah, disertasi, ensiklopedia, internet, dan sumber sumber lain [3]. Referensi tersebut berisikan tentang (1) Karakteristik seragam militer, (2) Pengaruh unsur militer pada masayrakat dan kalangan muda, (3) Fashion Techwear, dan (4) Utility, Modular

\section{Diskusi}

\subsection{Military Uniform}

Sejak awal Perang Dunia 1 gaya berpakaian atau disebut fashion telah dipengaruhi oleh seragam militer. Partisipasi atau keikutsertaan Amerika Serikat dalam perang tersebut telah memengaruhi desain, bahan atau kain, dan warna pada gaya berpakaian atau fashion saat ini [4]. Seperti yang dikutip dari buku Malcolm Barnard, pakaian, busana, kostum hingga dandanan dapat digolongkan kedalam suatu bentuk komunikasi artifaktual (artifactual communication) yang didefinisikan sebagai komunikasi yang berlangsung melalui pakaian dan penataan berbagai artefak misalnya, pakaian, dandanan, hingga perhiasan. Fashion, pakaian, atau busana mampu menyampaikan pesan-pesan nonverbal, maka ia dapat dikategorikan sebagai sebuah komunikasi nonverbal [5].

Pada dasarnya, seragam militer merupakan sebuah pakaian yang mewakili identitas suatu angkatan bersenjata. Terdapat berbagai sejarah dan konsekuensi yang melekat di balik tampilan visual seragam, dan tentu saja nama baik angkatan bersenjata yang dibawa oleh individu yang menggunakan seragam tersebut dimanapun ia berada [6]. Bila mengacu pada Kamus Besar Bahasa Indonesia, maka istilah karakteristik dalam penelitian ini adalah segala sesuatu yang mempunyai sifat khas sesuai dengan perwatakan tertentu. Oleh karenanya karakteristik militer adalah segala sesuatu yang mempunyai sifat khas sesuai dengan perwatakan militer. Perwatakan militer di sini dipahami dari berbagai bentuk visualisasi militer yang berasal dari seragam yang masih digunakan sebagai pakaian dinas maupun sudah tidak lagi digunakan dalam kedinasan militer [7].

\subsection{Military Fashion di Masyarakat}

Berdasarkan pada artikel yang dikutip, fashion adalah sebuah ekspresi diri yang memungkinkan setiap orang mencoba berbagai peran dalam hidup. Fashion adalah perubahan penting agar hidup dapat selalu menyenangkan [8]. Selama beranad-abad, individu atau kelompok masyarakat menggunakan pakaian sebagai alat komunikasi nonverbal untuk menjelaskan pekerjaan, strata sosial, status perkawinan, bahkan kekayaan mereka. Fashion adalah media untuk kebebasan berekspresi. Bukan hanya pakaian melainkan aksesoris, perhiasan, tata rambut, dan kecantikan. Apa yang dipakai dan bagaimana memakainya menjadi kunci untuk

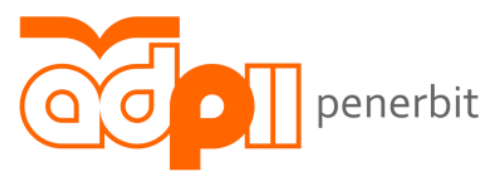

Penerbit Aliansi Desainer Produk Industri Indonesia 
secara mudah melihat situasi social yang dialami seseorang [9]. Fenomena penggunaan karakteristik militer oleh masyarakat sipil dimaknai bahwa walaupun kolonialisme telah berakhir lama namun bentuk-bentuk "representasi" yang membangkitkan endapan sindroma rasa rendah diri yang bersemayam dan terlestarikan pada alam bawah sadar individu poskolonial kontemporer Indonesia tetap terlestarikan [7]. Seperti yang dikutip dari buku Malcom Barnard tahun 1996, pakaian/busana di dalam kehidupan orang keseharian tidak sekedar hanya sekedar pemenuhan kebutuhan primer atau menjadi wujud ekspresi seni tata busana. Pakaian/busana juga dipakai sebagai alat untuk menciptakan kesan (sense) dan makna (meanings), hal ini mengacu pada pendapat Umberto Eco (dalam Barnard, 1996, vi) yang mengatakan 'I speak trough my cloth' [7]. Namun, mengenali keinginan masyarakat akan replika pakaian militer yang semirip mungkin maka produsen pakaian menciptakan replika pakaian militer serupa dengan seragam militer. Replika tersebut disebut dengan 'kostum' militer karena digunakan bukan sebagai seragam militer asli dan bagian dari kebijakan, melainkan karena kebutuhan permainan dan aktivitas sipil lainnya [6]. Menurut penulis, saat ini banyak sekali produsen fashion atau yang lebih dikenal sebagai brand fashion di Indonesia yang terinspirasi dari hal hal yang berkaitan dengan militer. Seperti contoh nya siluet jaket, celana panjang, topi, hingga ke siluet sepatu. Mereka berani mengambil langkah tersebut dan memproduksi barang fashion yang berkonsep military untuk ditawarkan kepada masyarakat. Seperti yang dikutip oleh penulis, hal tersebut berdasarkan pada seragam militer yang digunakan masyarakat sipil menjadi bukan 'seragam militer' lagi karena telah terjadi perubahan dari 'anti fashion' menjadi 'fashion' [10]. Hal tersebut menandakan bahwa produk pakaian atau hal hal yang berhubungan dengan militer saat ini sudah lebih berkembang lagi dan bukan hanya sebagai identitas para personil militer resmi.

Seperti yang dikutip dari buku rujukan, Perang Dunia pertama pada tahun 1914 - 1918 ternyata mengakibatkan dampak sosial yang sangat besar juga terhadap bidang Seni dan Desain [11]. Perubahan sosial masyarakat yang mengantar pada modernisme terlihat dengan jelas pada bidang kesenian, yang selanjutnya juga sangat dipengaruhi oleh kemajuan ilmu pengetahuan sebagai desakan hasrat manusia untuk menggali dunia ini. Hal ini disebabkan oleh kesadaran manusia akan pikiran dan hak untuk mengetahui ( diawali oleh kesadaran Rene Descartes terhadap Pikiran manusia ) [11]. Dari kutipan tersebut menjelaskan bahwa perubahan sosial masyarakat memang terjadi, khususnya pada penggunaan fashion di masyarakat luas yang sudah banyak menjurus atau memusat pada jenis fashion yang berasal dari military. Pada kutipan buku disebutkan bahwa perang dunia pertama mempengaruhi bidang seni dan desain, yang memang pada nyatanya semua aspek yang ada didunia ini tidak terlepas dari unsur seni dan desain. Termasuk juga hal hal yang berhubungan dengan military. Perubahan sosial masyarakat pada bidang fashion saat ini juga sangat dipengaruhi oleh unsur seni dan desain, terlebih lagi yang mendasari fashion itu sendiri adalah unsur seni dan desain. Pada unsur militer, semua aspek yang dituangkan pada produk jadi untuk kegiatan militer semuanya merupakan berdasarkan fungsi dari aktifitas kegiatan dan kebutuhan pasukan militer itu sendiri. Semua aspek tersebut harus memudahkan para pasukan militer dikarenakan digunakan pada medan tempur. Seiring perubahan dan perkembangan fashion unsur military tidak lagi hanya sebatas produk yang ditujukan untuk pasukan militer, namun juga digunakan dan dikembangkan untuk kebutuhan fashion yang dapat menghasilkan suatu pemikiran baru dan gaya fashion baru. Saat ini sudah banyak sekali brand atau merek bisnis fashion yang berkonsep military, hal tersebut didasarkan karena unsur military yang sangat bagus dan dapat dikembangkan lagi pada dunia fashion. Berdasarkan hal tersebut masyarakat secara langsung atau tidak langsung telah terpengaruh dengan hal hal yang berhubungan dengan military dan apabila masyarakat menyukai dan bahkan berubah gaya fashion nya mengikuti trend yang sedang berkembaang dan terjadi saat ini, dikarenakan pengaruh dari branding dari merek fashion yang memiliki konsep military tersebut. Ada beberapa merek atau brand Indonesia yang sangat berkembang dalam hal development product dan branding nya yang kuat dan memiliki konsep streetwear fashion dengan sentuhan unsur military style. Merek atau brand tersebut adalah Dominate Jakarta dan Orbit Gear. Brand tersebut merupakan karya anak muda Indonesia yang hasil produk nya cukup baik bahkan sangat baik jika dilihat dari segi kualitas dan design nya. Kemunculan brand tersebut di Indonesia sudah membuat movement besar bagi Industri Kreatif dalam negeri, bahkan menginspirasi anak muda lainnya untuk berfikir dan bergerak maju. Seperti salah satu brand atau merek fashion asal Jakarta yaitu Dominate Jakarta yang memiliki arti dominate yang bermakna sebagai menguasai atau mendominasi. Tujuan dari setiap brand yang

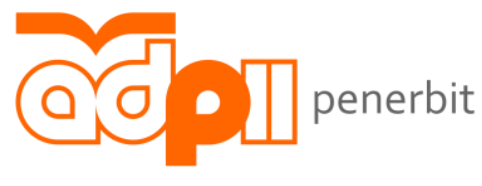

Penerbit Aliansi Desainer Produk Industri Indonesia 
dibuat adalah pasti untuk berkembang maju dan bermanfaat untuk banyak orang, dan maka dari itu nama dari setiap brand mempunyai andil besar terhadap brand tersebut kedepannya.

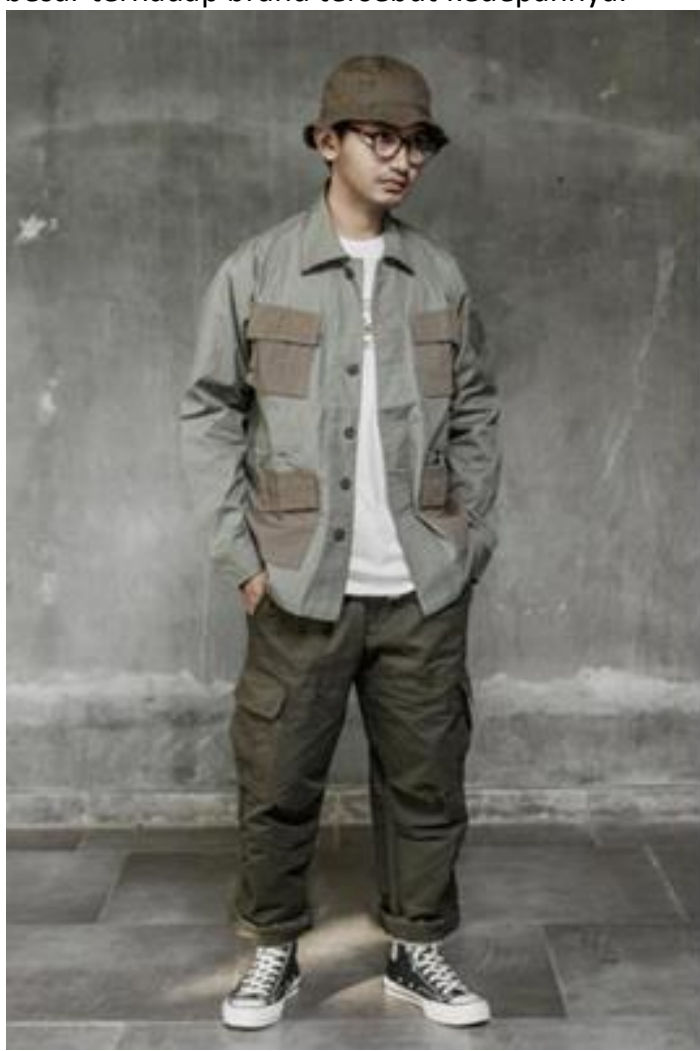

Gambar 1. Dominate Jakarta/Less Taiwan Capsule/Jacket https://hypebeast.com/2017/1/dominate-jakarta-less-taiwancapsule

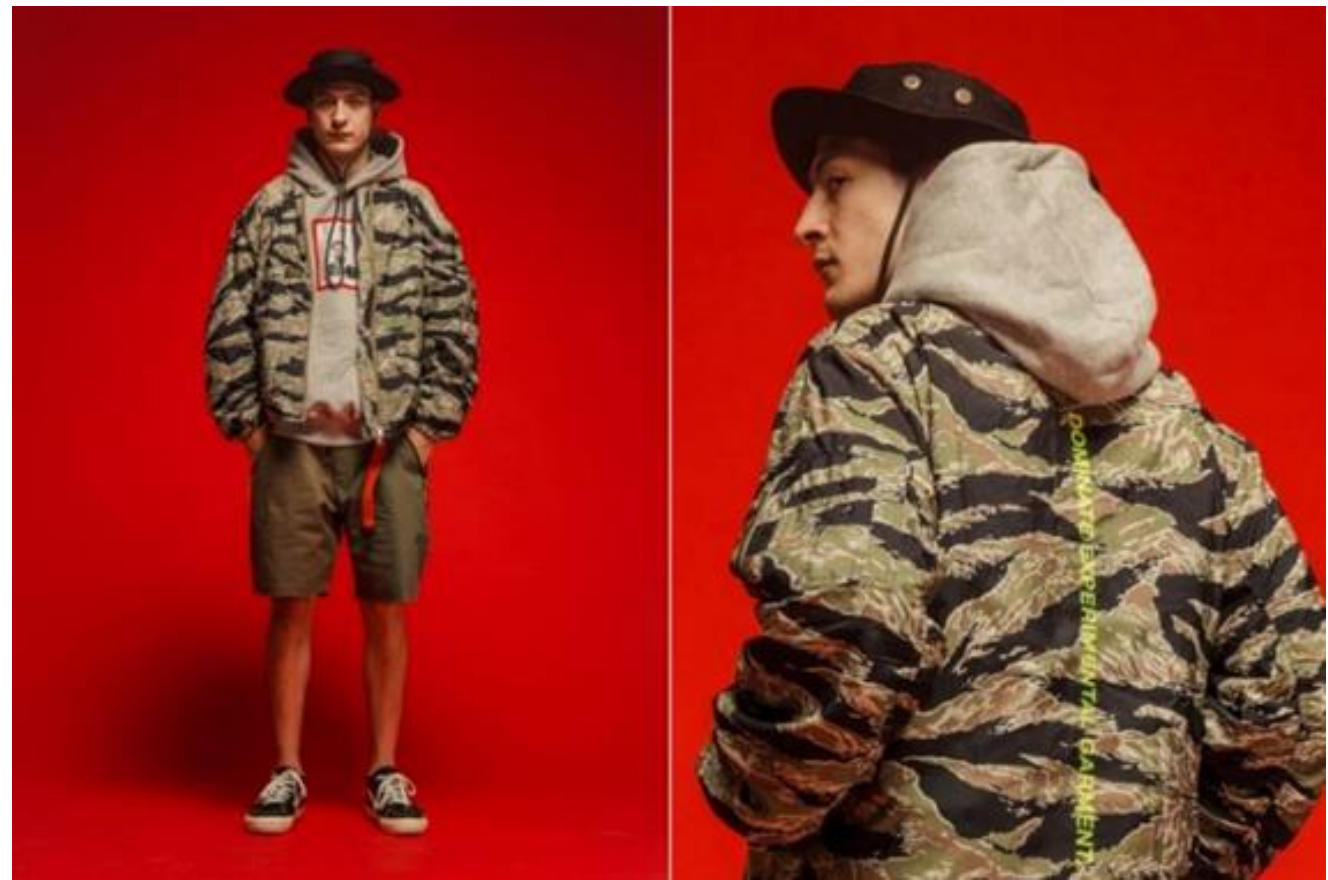

Gambar 2. Dominate Jakarta/Fall Winter 2019/Jacket https://hypebeast.com/2019/10/dominate-jakarta-fall-winter2019-lookbook-collection-release.

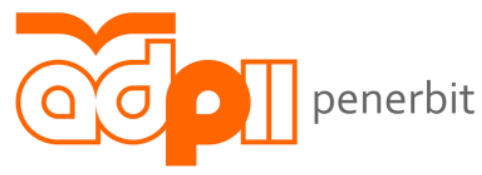

Penerbit Aliansi Desainer Produk Industri Indonesia 
Sama hal nya seperti Dominate Jakarta, ada brand asal Indonesia lagi yang menarik untuk dibahas karena memiliki konsep yang sangat baik, yaitu Orbit Gear yang merupakan brand teachwear dari Indonesia yang berfokus pada produk tas atau sarana bawa. Apabila menilik karakteristik dari techwear yang memiliki fitur anti air, kuat, muat banyak, dan breathability atau terdapat ruang untuk sirkulasi udara, merupakan paduan yang sempurna apabila dikombinasikan dalam suatu produk. Orbit Gear sendiri merupakan brand yang membuat produk sarana bawa dengan konsep technical gear yaitu sesuatu yang berhubungan dengan peralatan teknikal dan garment maker yaitu dapat membuat dan memproduksi bahan baku sendiri. Pada setiap produk yang dihasilkan memunculkan konsep idealis mereka yaitu techwear, serta memiliki unsur dan karakteristik military dengan modular system yaitu system lepas-pasang yang terdapat disetiap produk nya.

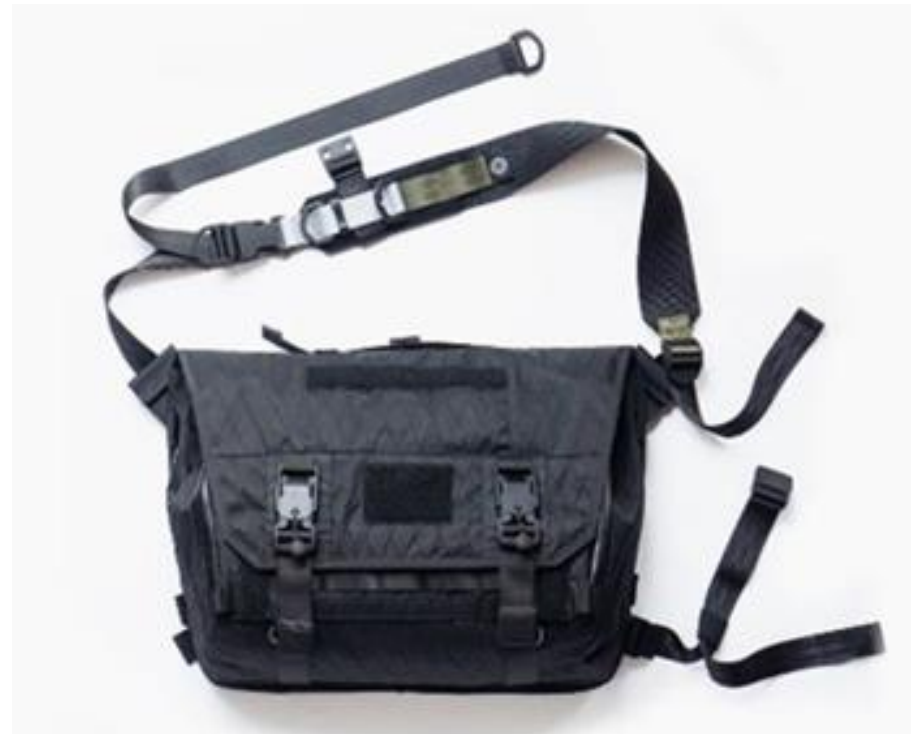

Gambar 3. Orbit Gear/Black Phoenix/Messenger Bag https://www.orbitgear.id/collections/all-gear/products/r221-vbwxbk-adv-black-phoenix-vb

Modular System yang ada pada produk Orbit Gear berupa pola jahitan webbing yang memiliki rongga yang berfungsi untuk akses lepas-pasang kompartmen tambahan atau kompartmen kecil. Sistem tersebut diadaptasi berdasarkan sarana bawa yang ada pada tas militer, di mana modular system tersebut juga terdapat pada tas militer.

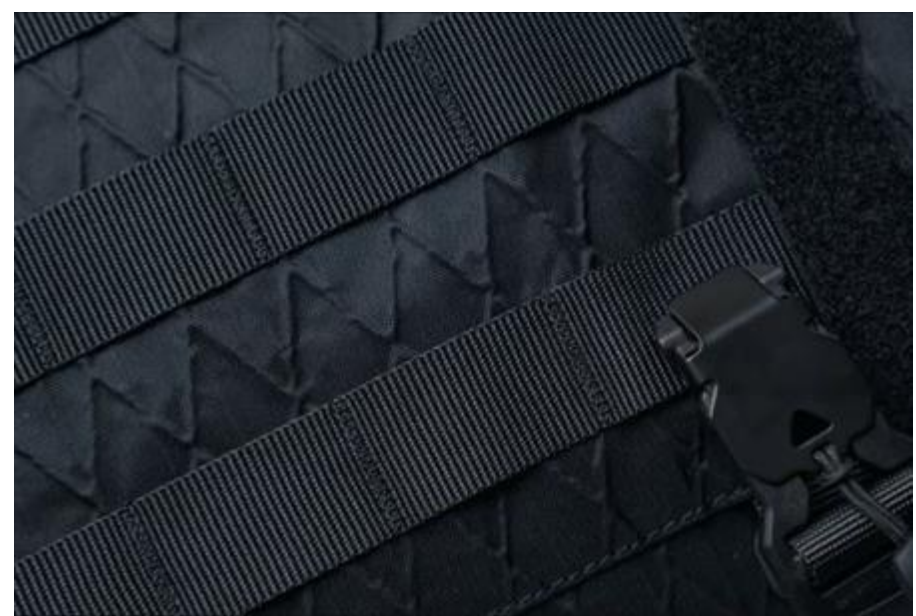

Gambar 4. Orbit Gear/Black Phoenix/Detail https://www.orbitgear.id/collections/all-gear/products/r221-vb-wxbk-advblack-phoenix-vb 


\subsection{Utility \& Modular}

Menurut artikel yang dikutip, pengertian utilitas adalah istilah untuk menggambarkan kepuasan konsumen yang diperoleh dari pengonsumsian baik itu jasa ataupun barang [12]. Banyak masyarakat yang menggunakan pakaian atau fashion yang berdasarkan unsur militer adalah karena karakteristik pakaian atau hal yang berkaitan dengan militer itu sendiri dan banyak dari masyarakat yang menyukai hal hal yang mengandung unsur military. Namun pada dasarnya, manusia ingin yang terbaik dalam berbagai aspek, salah satu nya terhadap fashion, hal tersebut di ukur berdasarkan tingkat kepuasan masing masing individu dalam menilai suatu barang. Seperti pada artikel yang dikutip oleh penulis, pada dasarnya kepuasan itu adalah suatu keadaan yang tidak bisa diukur karena ia adalah tingkat perasaan seseorang. Kepuasan konsumen merupakan suatu keadaan di mana kebutuhan, keinginan, dan harapan konsumen terpenuhi melalui produk yang dikonsumsinya [13].

Jika kita berbicara tentang fashion techwear, salah satu fungsi dan tujuan dari produk techwear yaitu adalah utility yang ada pada produk tersebut. Utility yang ada pada produk tersebut adalah bagaimana cara konsumen ingin membeli dan menilai produk tersebut, yang pada dasarnya produk tersebut bukan jenis fashion yang semua orang suka dan bisa pakai. Apabila seseorang membeli dan mempunyai produk dari fashion techwear, maka dapat dinilai bahwa orang tersebut menyukai hal-hal yang berhubungan dengan outdoor gear \& military. Nilai utility tersebut didapatkan dengan cara menilai bahwa konsumen membeli produk fashion techwear yang berbeda dari yang lainnya, dengan kata lain konsumen tersebut ingin tampil berbeda dan terbaik.

Misalnya pada produk tas techwear, produk tersebut merupakan desain produk yang dihasilkan dari pola pikir yang menghasilkan desain produk sarana bawa dengan fitur yang lengkap dan memudahkan pengguna nya dan salah satu fitur tersebut adalah fitur modular. Seperti pada artikel yang penulis kutip, istilah modular dalam seni rupa pertama disebutkan dalam ensiklopedia seni Jerman tahun 1975 sebagai " bentuk seni yang dibuat dengan komponen yang bisa bergerak, mengubah objek menjadi kondisi baru sebagai akibat pemindahan bagian-bagiannya" [14].

"Modular art is art created by joining together standardized units (moduls) to form larger, more complex compositions. In some works the units can be subsequently moved, removed and added to - that is, modulated - to create a new work of art, different from the original or ensuing configurations" [14].

Berdasarkan pembahasan yang telah disebutkan diatas, penulis dapat menyebutkan bahwa fitur yang ada pada produk tas fashion techwear mengadaptasi konsep modular tersebut. Selain itu, pada penerapan nya hal-hal yang berhubungan dengan military juga mengadopsi konsep modular tersebut. Karena berdasarkan kebutuhan dan urgensi nya, barang bawaan pada tas militer dapat di tambah-kurangi atau di lepas-pasang dengan cara menggunakan pouch kecil atau kompartmen tambahan yang dibuat dengan system modular. Penerapan atau penggunaan system tersebut merupakan suatu kebaruan desain yang mengadopsi system tas militer yang kemudian dipadukan dengan fashion. Hal tersebut mempermudah pengguna nya karena dapat disesuaikan dengan kebutuhan pengguna nya, karena system modular yang dapat di lepas - pasang bagian bagian nya, dengan unsur utility yang membuat pengguna produk fashion techwear tersebut menjadi lebih puas terhadap produk atau barang yang mereka gunakan. Seperti pada contoh produk sarana bawa berikut ini yang memiliki fitur kompartmen dengan pola jahitan nylon webbing yang dijahit berbentuk lurus namun diberi ruang atau rongga yang berfungsi untuk melepas pasang kompartmen atau pouch tambahan. Fitur tersebut sangat berfungsi karena dapat menyesuaikan sesuai kebutuhan pengguna apabila ingin membawa barang yang lebih banyak, atau barang yang lebih sedikit pada tas.

Pada system modular atau sistem lepas-pasang yang terdapat pada sarana bawa techwear memiliki rangkaian atau system pada bagian belakang pouch atau kompartmen tambahan. Pada bagian belakang pouch tersebut memiliki system berupa nylon webbing atau strap berbahan nilon yang dijahit sejajar dengan pola jahitan nylon webbing yang berongga pada kompartmen utama. Webbing system atau pola jahitan strap tersebut berfungsi untuk memudahkan proses lepas-pasang atau disebut dengan modular. Penggunakan plastic hardware YKK

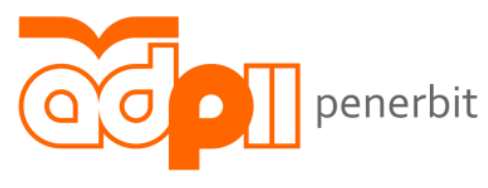

Penerbit Aliansi Desainer Produk Industri Indonesia 
atau sejenisnya yang memiliki kualitas terbaik sangat membantu secara optimal dalam mengaplikasikan system modular atau sistem lepas-pasang tersebut.
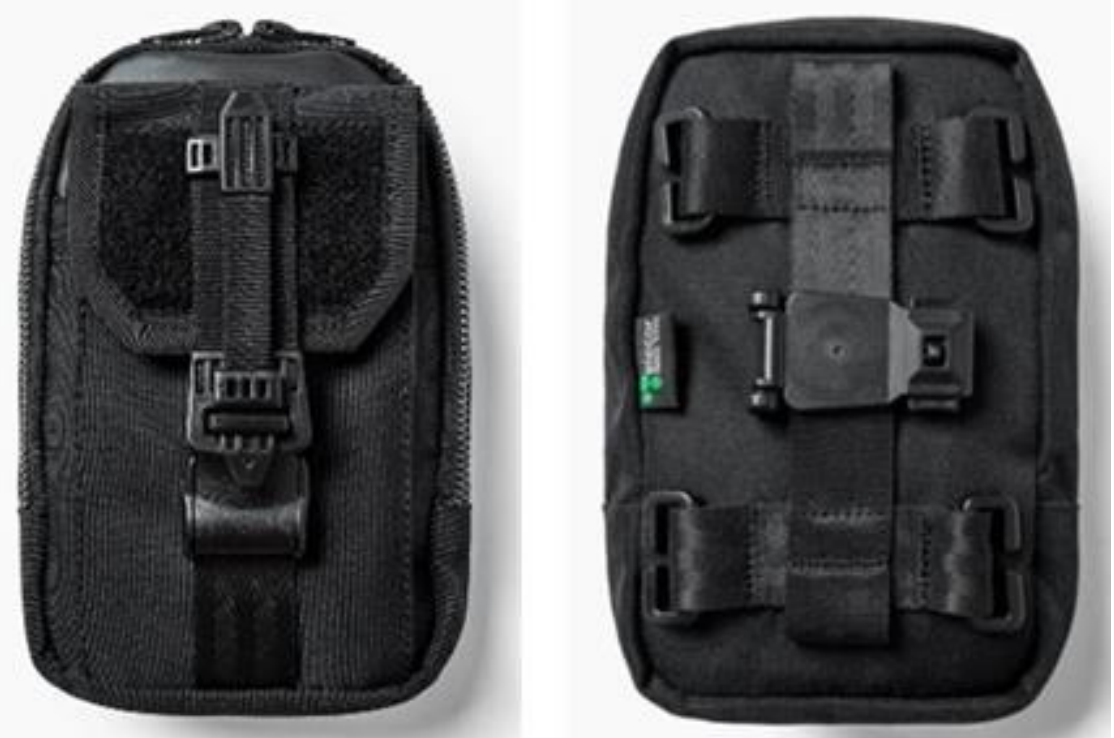

Gambar 5. Orbit Gear/OG Pouch/Detail https://www.orbitgear.id/collections/all-gear/products/mod-301-sp-bk-ogpouch.

Pada proses implementasinya, penulis melakukan pembuatan prototipe sarana bawa untuk kepentingan perkuliahan yang sudah dilakukan dan dirancang dengan baik yang mengacu pada fashion techwear. Prototipe sarana bawa tersebut diperuntukkan guna penilaian hasil capaian proses desain yang dirancang. Sarana bawa yang dibuat prototipenya berjenis messenger bag, karena konsep perancangan sarana bawa yang dirancang penulis mengacu kepada kebutuhan user yang hobi dan beraktifitas sehari-hari menggunakan sepeda fixed gear. Sarana bawa atau messenger bag tersebut didesain dan dirancang dengan mengusung konsep kebaruan dengan tema techwear untuk jenis tas messenger bag khusus untuk user sepeda fixed gear.
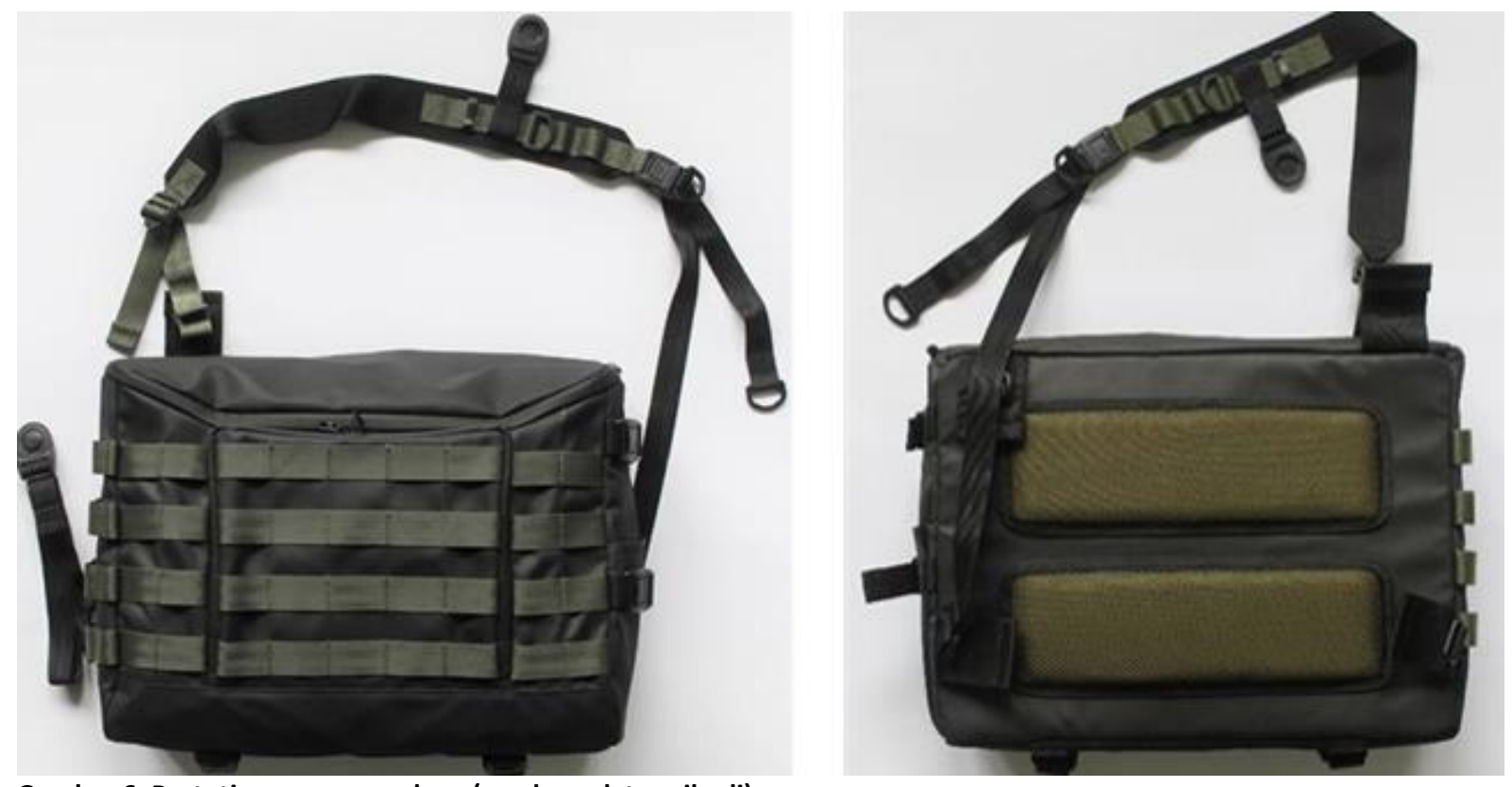

Gambar 6. Prototipe messenger bag. (sumber : data pribadi)

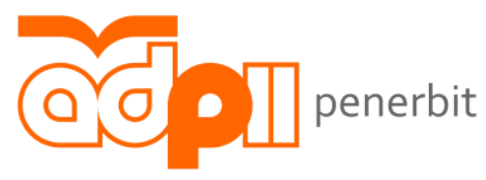

Penerbit Aliansi Desainer Produk Industri Indonesia 
Pemilihan desain messenger bag tersebut berdasarkan peluang kebaruan karena belum ada yang merancang produk messenger bag dengan unsur tema dan konsep techwear khusus untuk user sepeda fixed gear. Pada prototipe yang dibuat, terdapat beberapa fitur-fitur yang mengacu pada techwear itu sendiri, seperti modular system, quick release buckle, waterproof material, comfortable back system. Seperti strap system yang dirancang yaitu dengan system lepas-pasang dengan fungsi untuk dapat diubah posisi pemakaiannya ke sebelah kanan atau kiri, sesuai kebutuhan dan posisi pakai user itu sendiri. Ada juga quick-fit system yaitu berupa system pada strap yang dapat dikencangkan dan dikendurkan atau release dengan mudah. Selain itu ada fitur modular attachment seperti pouch dan organizer yang dapat dilepas-pasang, melalui system modular pada bagian belakang pouch tersebut.

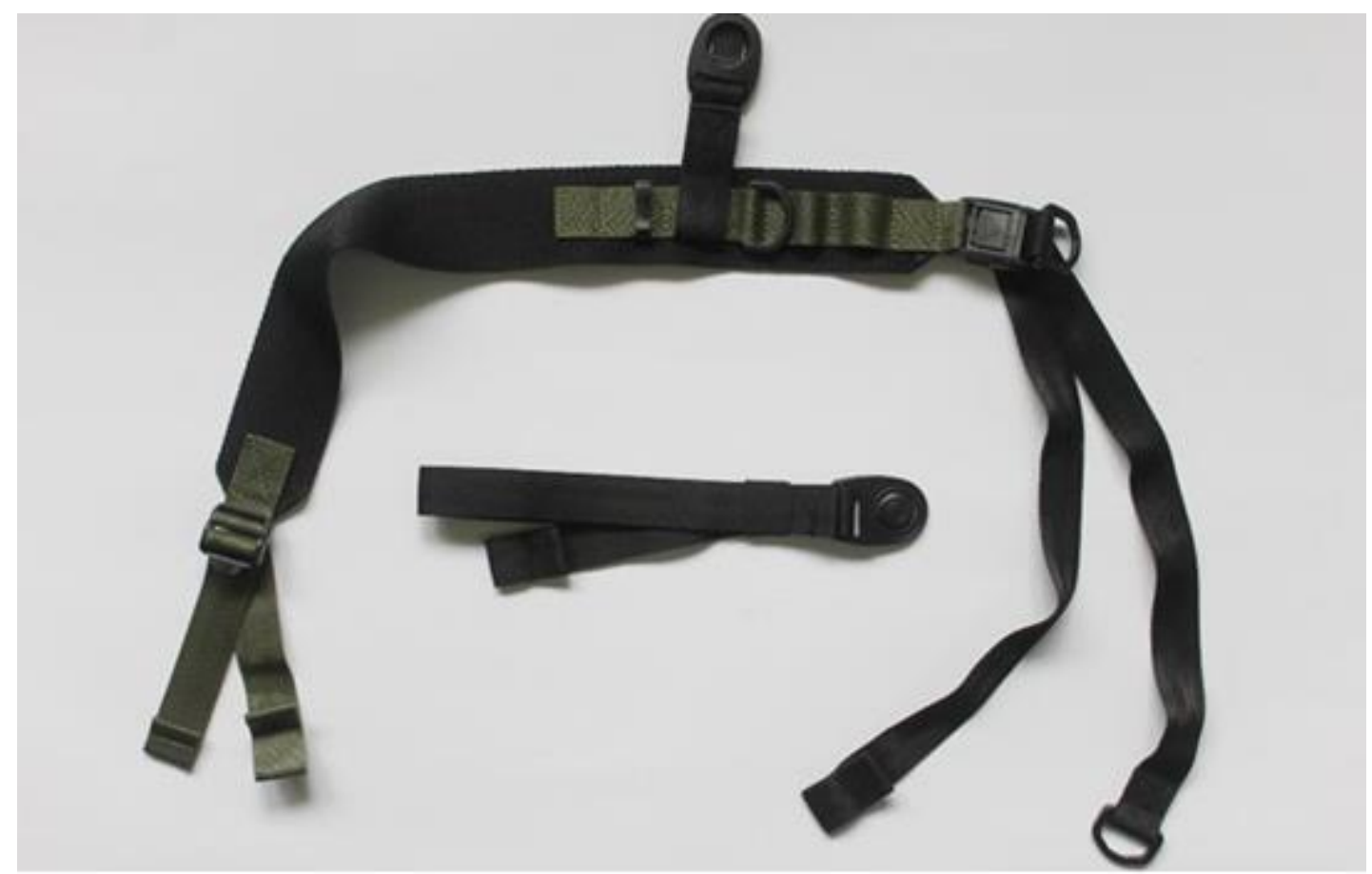

Gambar 7. Prototipe messenger bag/modular attachment strap. (sumber : data pribadi)
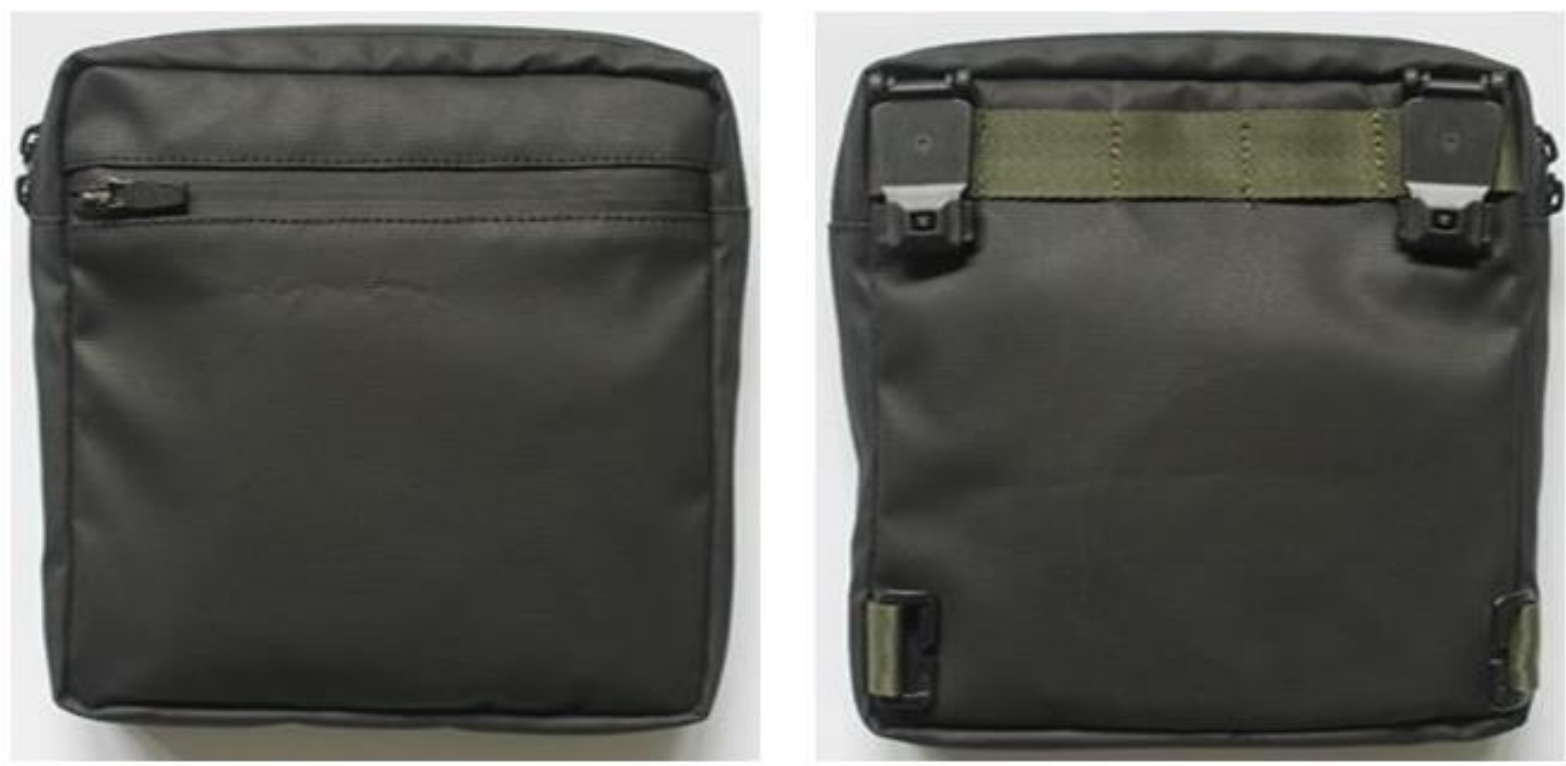

Gambar 8. Prototipe messenger bag/modular attachment pouch. (sumber : data pribadi)

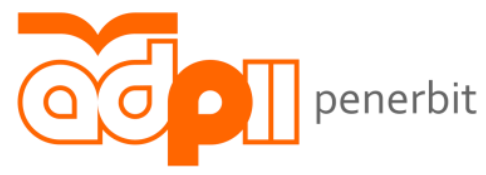

Penerbit Aliansi Desainer Produk Industri Indonesia 


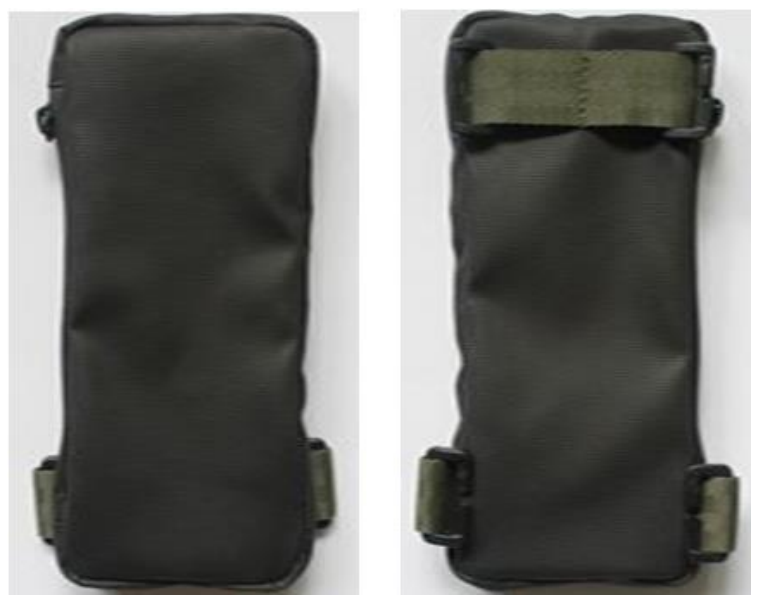

Gambar 9. Prototipe messenger bag/modular attachment mini pouch. (sumber : data pribadi)

Untuk pouch yang dirancang merupakan fitur-fitur pelengkap untuk desain rancangan messenger bag tersebut. Mengacu pada system yang ada pada military gear yaitu fitur molle system, yaitu system yang dimana bagian tambahan tas military dapat dilepas-pasang menggunakan pola ikatan webbing dibagian belakang pouch. Namun pembaruan desain yang dilakukan adalah dengan menggunakan plastic hardware untuk memudahkan rancangan tas messenger bag. Fungsi dari pouch itu sendiri adalah sebagai kompartmen organizer atau barangbarang kecil yang dapat dipertimbangkan untuk digunakan atau tidak. Peran dari fitur-fitur modular tersebut juga mengacu pada karakteristik techwear sebagai trend urban fashion dengan unsur tactical, outdoor \& military gear sehingga aspek visual \& aesthetic harus tepat dan sesuai dengan techwear itu sendiri.

\section{Kesimpulan.}

Berdasarkan pembahasan diatas mengenai pengaruh unsur military pada masyarakat khususnya kalangan muda di Indonesia dapat disimpulkan bahwa saat ini banyak yang sudah lebih mengenal tentang fashion dan perkembangannya terbilang cepat terlebih lagi pada kalangan muda di Indonesia. Hal tersebut dipengaruhi oleh perkembangan zaman yang saat ini segala informasi sudah dapat diakses dengan sangat cepat dan tersebar dengan sangat luas. Ditambah lagi dengan muncul nya brand atau merek fashion di Indonesia yang berkonsep military, hal tersebut secara langsung mempengaruhi dan menambah informasi para kalangan muda di Indonesia tentang perkembangan fashion terkini. Ada beberapa merek atau brand fashion Indonesia yang berkembang pada area military fashion dan techwear. Produk-produk yang dihasilkan oleh brand atau merek tersebut memiliki karakteristik yang berhubungan dengan military. Unsur-unsur yang terdapat didalam military yang diadaptasi dan dipadukan dengan fashion techwear yaitu versatile atau multi fungsi, modular atau sistem lepas pasang, dan large capacity atau kompartment yang besar dan muat banyak. Didalam aspek tersebut masih banyak ruang untuk di ekplorasi lebih dalam secara desain dan fashion. Dengan adanya fashion techwear yang baru muncul dan berkembang di Indonesia, membuat trend fashion tersebut menarik untuk dibahas lebih dalam lagi. Selain itu masyarakat Indonesia tergolong cukup konsumtif terhadap segala sesuatu, terutama dalam hal fashion yang membuat trend fashion yang baru muncul tersebut dapat diterima pada masyarakat Indonesia terlebih lagi pada kalangan muda nya.

\section{Referensi}

[1] D. Ortega, "REPRESENTASI KARAKTERISTIK MILITER PADA MASYARAKAT SIPIL DI SURABAYA," J. DKV Adiwarna, vol. Vol 1, no. 10, p. 16, 2017.

[2] M. Berkarya, "Sejarah Awal Mula Kemunculan dan Perkembangan Tas," Medium, Dec. 08, 2016. https://medium.com/@MudaBerkarya221B/sejarah-awal-mula-kemunculan-dan-perkembangan-tas7d139dcaf4b1 (accessed Mar. 10, 2021).

[3] G. link, Facebook, Twitter, Pinterest, Email, and O. Apps, "Pengertian Studi Kepustakaan." https://www.transiskom.com/2016/03/pengertian-studi-kepustakaan.html (accessed Mar. 10, 2021).

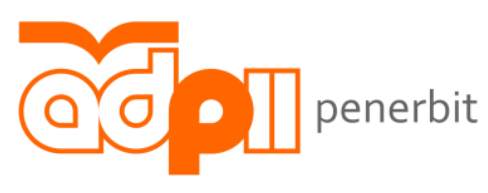

Penerbit Aliansi Desainer Produk Industri Indonesia 
[4] L. Topor, "War and fashion: Political views and how military styles influence fashion," p. 65.

[5] F. A. Feisol, "STREETWEAR SEBAGAI IDENTITAS BUDAYA MASYARAKAT URBAN (Studi Deskriptif," Jurnal Ilmu Komunikasi UPN Veteran Jatim , p. 2, 2018.

[6] D. Ortega, A. Dektisa and B. D. Arini, "REPRESENTASI KARAKTERISTIK MILITER PADA MASYARAKAT SIPIL DI SURABAYA," p. 6.

[7] A. Dektisa, "Eforia Mencecap Rasa Militer," pp. 1-2, 2019.

[8] B. Tyaswara, R. R. Taufik, M. Suhadi and R. Danyati, "PEMAKNAAN TERHADAP FASHION STYLE REMAJA DI BANDUNG," Jurnal Komunikasi, vol. VIII, no. 3, p. 4, 2017.

[9] B. Tyaswara, R. R. Taufik, M. Suhadi and R. Danyati, "PEMAKNAAN TERHADAP FASHION STYLE REMAJA DI BANDUNG," Jurnal Komunikasi, vol. VIII, no. 3, p. 2, 2017.

[10] D. Ortega, A. Dektisa and B. D. Arini, "REPRESENTASI KARAKTERISTIK MILITER PADA MASYARAKAT SIPIL DI SURABAYA," p. 12.

[11] A. Masri, Strategi Visual, Jalasutra, Jogjakarta. 2010.

[12] A. Barakah, "UTILITAS DALAM PERILAKU KONSUMEN PERSPEKTIF NILAI KEISLAMAN," p. 3.

[13] A. Barakah, "UTILITAS DALAM PERILAKU KONSUMEN PERSPEKTIF NILAI KEISLAMAN," p. 4.

[14] N. S. D. Putra and A. J. Irianto, "Dualisme Modular," vol. IX, no. 2, p. 2, 2017.

[15] A. Dektisa, "Eforia Mencecap Rasa Militer," p. 16.

[16] A. Barakah, "UTILITAS DALAM PERILAKU KONSUMEN". Jurnal Studi Keislaman. Volume 4, no. 2 Desember. 2018. 